\title{
Investigation of the Interpersonal Metafunction in A S Ogundimu's A Silly Season
}

\author{
Noureni Boukari \\ Department of English, University of Parakou, Benin Republic (West Africa) \\ E-mail: bouk_nour@yahoo.fr
}

Received: September 17, 2020 Accepted: November 20, 2020 Published: November 27, 2020

doi:10.5296/elr.v6i2.17999

URL: https://doi.org/10.5296/elr.v6i2.17999

\begin{abstract}
People use language to interact. In interacting, they take various social roles. Grasping the specific roles thus played by interactants and their implications in a text is the finality of the study of the interpersonal metafunction in Systemic Functional Linguistics. This paper explores the interpersonal metafunction in A silly season, a novel by A. S. Ogundimu. Based on text exploration for mood patterns, especially the choice of mood types and modality features, the investigation reveals unusual tenor dimensions in the corpus under consideration. It ultimately appears that $A$ silly season is not just about bribery, but it mostly relates some social malaise and threat of disruption due to a single individual's firm attempt to sow or restore the sense of rectitude within a corrupt, rotten society.
\end{abstract}

Keywords: Bribery, Pressure, Interpersonal metafunction, Mood patterns, Tenor of discourse

\section{Introduction}

Systemic Functional Linguistics (hereafter SFL) can help to understand any text or discourse under three angles: the experiential meaning, the interpersonal meaning and the textual meaning. These three types of meanings are also referred to as the three metafunctions of language (Eggins, 2004). By applying SFL to study a text, one may investigate either the three metafunctions, or two, or only one of them. The present study is an inquiry into the interpersonal metafunction of language as used in A silly season (2008), a contemporary Anglophone African novel written by Nigerian Adetunji Ogundimu who is author of many other novels.

Any reader can realize that $A$ silly season is about corruption. Set in a town of a West African country (Nigeria), A silly season is the story of a humble, honest teacher unexpectedly appointed at the political post of Commissioner, who undergoes the pressure of his mother and relatives insistently telling him to take bribes and never consider resigning from the post no matter what tribulations he may face. When Gbaguidi (2018) writes that the [main] 
character of this novel "vehemently resists a rampant social phenomenon and is regarded as the odd-man-out", the phenomenon he refers to is bribery indeed. So, the novel depicts a community with a particular interactant singled out for "swimming against the tide", that is, categorically rejecting bribes. From the study of the interpersonal metafunction, we can evaluate the role relationships between this particular interactant and the others. That evaluation will hopefully contribute to further understanding the message conveyed through the fictional world under consideration. With this aim in view, the theoretical framework is synoptically presented below, followed by a literature review, a clarification of the methodological approach, and the practical analysis - which includes data presentation, the discussion and the recapitulation of the main findings.

\section{Theoretical Framework: Synopsis of the Theory of Mood}

To grasp the theory of the interpersonal metafunction, one needs to be familiar with the SFL-based semantics of interaction. Eggins (2004) begins the explanation of this semantics by recalling that we use language to exchange two kinds of 'commodity': on the one hand, information; on the other hand, goods and services. The way clauses are organized in exchanging information is called the grammatical structure of propositions; the way they are organized in exchanging goods and services is referred to as the grammar of proposals. However, here in this paper, without separating the two "grammars" as such, we essentially consider the broad lines, by recalling some of the key technical aspects that we deem virtually indispensable as regards the theory of Mood, i.e. the grammar of interpersonal meaning. Those broad lines include: Mood types and speech functions; the functional constituents of clauses; Tenor of discourse: its dimensions.

\section{- Mood types and speech functions}

In traditional grammar, it is commonly known that there are four basic clause Mood types: the declarative mood (which is meant to make statements), the interrogative (meant to ask questions), the imperative (meant to make commands), and the exclamative (used to express emotions: surprise, disgust, joy, etc.). However, in the grammar of interpersonal meaning, it is noteworthy, as stated by Eggins (2004), that "when we are acting on or for other people, we do not only have the dogmatic choice of do or don't do, I'll give you this or I won't give you this". When the context requires, modality devices (succinctly explained below in this subsection), may be used to form, for example, the modulated interrogative and substitute it for the imperative, the modulated declarative and substitute it for the interrogative, and so on. Hence, the following table devised by Eggins (2004):

Table 1. Speech functions and typical or non-typical clause mood (Source $=$ Eggins 200)

\begin{tabular}{lll}
\hline Speech function & Typical clause Mood & Non-typical clause Mood \\
\hline \multirow{2}{*}{ Command } & Imperative & Modulated interrogative \\
& & Declarative \\
Offer & Modulated interrogative & Imperative declarative \\
Statement & Declarative & Tagged declarative \\
Question & Interrogative & Modulated declarative \\
\hline
\end{tabular}


In addition, when a piece of speech is made, more often than not, we expect some response, which may be either supporting or confronting. For example, when a speaker makes a statement, their interlocutor may make another statement standing either for an acknowledgement or for a contradiction. When a question is asked, the response may be either an answer or a disclaimer. Thus, we have the following table adapted from Eggins (2004:146), whose initial source is said by Eggins herself to be Halliday (1994:69).

Table 2. Speech function pairs (initiations and responses)

\begin{tabular}{lll}
\hline \multirow{2}{*}{ Initiating speech function } & Responding speech function & \\
\cline { 2 - 3 } Statement & Supporting & Confronting \\
Question & Acknowledgement & Contradiction \\
Offer & Answer & Disclaimer \\
Command & Acceptance (may be non-verbal) & Rejection \\
\hline
\end{tabular}

\section{- The functional constituents of clauses}

In the grammar of interpersonal meaning, the two main parts of a full clause are MOOD and RESIDUE. Considering all the individual elements of a clause, it consists of Subject, Finite (the auxiliary or any word playing the role of auxiliary), Predicator (the main verb), Complement and Adjunct (adverbial or prepositional phrase which contributes some additional information to the clause). The combination of Subject and Finite makes up the MOOD of the clause while the combination of the Predicator, Complement and Adjunct is referred to as the RESIDUE.

There are three broad classes of Adjuncts: Circumstantial Adjuncts (which add ideational meaning to the clause), Textual Adjuncts (Conjunctive Adjuncts and Continuity Adjuncts adding to textual meaning), and Modal Adjuncts (which add interpersonal meaning to the clause). Modal Adjuncts are subdivided into four main types, according to Eggins (2004:160-62) based on Halliday and Matthiessen (2004): (1) Mood Adjuncts (expressions of probability, usuality, intensification or minimization, presumption, inclination); (2) Polarity Adjuncts ("Yes" and "No"); (3) Comment Adjuncts (expressions of admission, assertion, how desirable...); (4) Vocative Adjuncts (designation of a likely 'next speaker').

Regarding modality, it comprises modalisation and modulation. A clause gets modalized when it contains a Finite modal operator expressing probability ("might, may, could, must...") or / and a Mood Adjunct of probability or usuality ("perhaps / probably / certainly / I think / I'm sure / It is certain that / It is probable that; sometimes / usually / always..."). It gets modulated when it contains a Finite modal operator or a complex Predicator expressing obligation or necessity ("must / should / need / shall...; be obliged to / be required to") or inclination ("be determined to"). Following Eggins' (2004) explanation of modality, which is based on Halliday and Matthiessen's (2004:147-50 and 617-21), it can be kept in mind that modalizers are finite modal operators expressing probability, and Mood Adjuncts of certainty or usuality; modulators are finite modal operators (or complex modulated predicators - if any) which express obligation or inclination. Both modalization and modulation patterns reflect 
speakers' judgements or attitudes, and that depends on the tenor of discourse.

\section{- Tenor of discourse : its dimensions}

Tenor is defined as "the social role relationships played by interactants, such as

student/lecturer, friend/friend" (Eggins 2004). Poynton (1985), reported by Eggins, has suggested that tenor can be broken down into three different continua, i.e. dimensions: power (equal vs unequal), contact (frequent vs infrequent / occasional), and affective involvement (high vs low). Indeed, these dimensions of tenor impact on language use in many significant ways. According to their role relationships, the interactants may use either informal language or formal language. Informal language means, for example, using vocative Adjuncts in the form of nicknames or given names reciprocally, making typical mood choices, using modalization to express probability, using modulation to express opinion. Formal language means, for example, not using vocatives reciprocally or not using them at all, making incongruent mood choices, using modalization to express suggestion.

So, the practical part of this paper will essentially consist in looking into the functioning of Mood types and modality items in the text(s) under study, so as to come up with the tenor of discourse and, eventually, the interpersonal metafunction. Prior to that, let us review a few research works that can be rated if not as models, at least as being of the same nature as the present article.

\section{Literature Review and Methodological Approach}

There have been numerous cases of investigation of the interpersonal metafunction in various genres of discourse. Some are concerned with literary artifacts. That is the case of Amoussou (2015), Koussouhon and Dossoumou (2015), Koutchadé (2016), Kossouhon and Boukari (2017), to name but a few. Others are public speech analysis; for instance, Ye (2010), Olaniyan (2012), Nur (2015), Djimet and Alladoun (2019). Still others, such as Ayoola (2013) and Taiwo (2014), are inquiries into political advertisements and manifestos.

The present study is an exploration of a literary artifact. It looks into a series of passages culled from a novel. The passages are selected almost from the beginning to the end of the said novel. They are explored thanks to both quantitative analysis and qualitative analysis. The quantitative analysis starts with the statistics of the linguistic items at stake, and includes some hypotheses. The qualitative analysis consists of a critical discussion resulting in inferences that (in)validate the hypotheses. Besides, this paper considers and evaluates the propositional import of the clause, that is, the significance of propositions and proposals in the interaction under analysis.

\section{Application: Text Analysis}

The passages that have been selected by way of corpus are presented in this section, showing my identification (underlining) of the specific linguistic items at stake. Then follows the discussion.

\subsection{Data Selection and Processing}

Key:

Pass $=$ Passage $; \mathrm{F}=$ Finite, $\mathrm{Fms}=$ modalized Finite, $\mathrm{Fml}=$ modulated Finite $; \mathrm{A}=$ Adjunct, Ao $=$ comment Adjunct, Ap = polarity Adjunct, Am = mood Adjunct, Av = vocative Adjunct, At 


\section{Macrothink}

$=$ continuity Adjunct.

Set i

\begin{tabular}{llll}
\hline Pass $\mathrm{N}^{\circ}$ & Passage & Addresser & Addressee \\
\hline 1 & ${ }^{1}$ You have to $(\mathbf{F m l})$ do something for our friends. & Abeji & Kunle \\
& (chap.3, p.17, line 12) & & \\
2 & ${ }^{2}$ I know $(\mathbf{A m})$ you cannot $(\mathbf{F m l})$ run away from reality. ${ }^{3}$ You & Abeji & Kunle \\
& $\underline{\text { must }(\mathbf{F m l}) \text { appreciate those who support you by giving }}$ & & \\
& them something reasonable. & & \\
& $($ chap.3, p.18, lines 14 to 17) & & \\
\hline
\end{tabular}

Set ii

\begin{tabular}{|c|c|c|c|}
\hline 3 & $\begin{array}{l}{ }^{1} \text { Look }(\mathbf{A t}), \underline{\text { Kunle }}(\mathbf{A v}){ }^{2} \text { Don't turn down handsome offers. } \\
\text { (chap.4, p.20, lines } 14 \text { and 15) }\end{array}$ & Akwa & Kunle \\
\hline 4 & $\begin{array}{l}{ }^{3} \text { Look }(\mathbf{A t}), \text { old boy }(\mathbf{A v}), \text { everybody steals. } \\
(\text { chap.4, p.21, line 12) }\end{array}$ & Akwa & Kunle \\
\hline 5 & $\begin{array}{l}{ }^{4} \text { No }(\mathbf{A p}), \underline{\text { Akwa }}(\mathbf{A v}) .{ }^{5} \mathrm{I} \text { will }(\mathbf{F m l}) \text { collect nothing. }{ }^{6} \text { Things must } \\
(\mathbf{F m l}) \text { change in this country. } \\
\text { (chap.4, p.24, lines } 12 \text { and } 13)\end{array}$ & Kunle & Akwa \\
\hline
\end{tabular}

\section{Set iii}

$6 \quad{ }^{1}$ Do you want to die a homeless pauper like your father? ${ }^{2}$ Why do Mother Kunle you drive away people who bring money to you? ${ }^{3}$ When do you want to enjoy your life? ${ }^{4}$ When do you want to draw on government? ${ }^{5}$ When do you want to use your power as commissioner? ${ }^{6}$ Do you know what people call government? (chap.6, p.34, lines 9 to 16)

$7 \quad{ }^{7}$ Did your father and I waste our time and resources sending you to school? ${ }^{8}$ Were we not investing our money to yield fruit? ${ }^{9} \mathrm{Can}$ 't $(\mathbf{F m l})$ you reason? ${ }^{10} \mathrm{Can}$ 't $(\mathbf{F m l})$ you learn anything from your father's woes? ${ }^{11}$ Can't $(\mathbf{F m l})$ you talk to your head? ${ }^{12}$ Please (Ao) son (Av), don't go astray. ${ }^{13}$ You heard Akwa, didn't you? ${ }^{14}$ Are you not friends? (chap.6, p.36, lines 6 to 12)

$8 \quad{ }^{15}$ What is wrong with you? ${ }^{16}$ Do you know what you're toying Mother Kunle with? ${ }^{17}$ Do you know what you will (Fms) lose? ${ }^{18}$ Look at this luxurious office; ${ }^{19}$ you want to lose it? ${ }^{20}$ You also want to throw yourself out of Oke-Aleebu Quarters? ${ }^{21}$ That's unreasonable. ${ }^{22}$ Some people are looking for jobs and cannot (Fml) find any; but you are lucky to have a good one and you want to quit? ${ }^{23}$ Don't you know anything about a bird in hand?

Mother Kunle (chap.18, p.118, lines 12 to 20) 


\section{Macrothink}

Set iv

\begin{tabular}{|c|c|c|c|c|}
\hline 9 & 9.1 & ${ }^{1}$ What's annoying? & Kunle & $\begin{array}{l}\text { Auntie } \\
\text { Toun }\end{array}$ \\
\hline & 9.2 & $\begin{array}{l}{ }^{2} \text { You don't know? }{ }^{3} \text { Then what is this story I am hearing about you } \\
\text { rejecting gifts? }\end{array}$ & $\begin{array}{l}\text { Auntie } \\
\text { Toun }\end{array}$ & Kunle \\
\hline & 9.3 & ${ }^{4}$ Is that so important? & Kunle & $\begin{array}{l}\text { Auntie } \\
\text { Toun }\end{array}$ \\
\hline & 9.4 & ${ }^{5}$ Is that not important? $[\ldots]$ & $\begin{array}{l}\text { Auntie } \\
\text { Toun }\end{array}$ & Kunle \\
\hline & 9.5 & $\begin{array}{l}{ }^{6} \text { Okay }(\mathbf{A t}) \underline{\text { Auntie }}(\mathbf{A v}) ; \text { but we have to }(\mathbf{F m l}) \text { reap slowly. }{ }^{7} \text { I must } \\
(\mathbf{F m l}) \text { be careful. } \\
\text { (chap.6, p.38, lines } 6 \text { to } 15)\end{array}$ & Kunle & $\begin{array}{l}\text { Auntie } \\
\text { Toun }\end{array}$ \\
\hline 10 & & $\begin{array}{l}{ }^{8} \text { You must }(\mathbf{F m l}) \text { reap slowly. }{ }^{9} \text { I mean you must }(\mathbf{F m l}) \text { take your } \\
\text { time; don't ever }(\mathbf{A m}) \text { go out of your office to demand for money. } \\
{[\ldots]{ }^{10} \text { However, when people bring money to you, you must }(\mathbf{F m l})} \\
\text { grab it. } \\
\text { (chap.6), p.38, lines } 17 \text { to } 20)\end{array}$ & $\begin{array}{l}\text { Auntie } \\
\text { Toun }\end{array}$ & Kunle \\
\hline 11 & & $\begin{array}{l}{ }^{11} \text { Bribes? }{ }^{12} \text { What is wrong with your head? }{ }^{13} \text { What do you call } \\
\text { bribes? }{ }^{14} \text { What is the difference between bribe money and gift } \\
\text { money? } \\
\text { (chap. } 6 \text {, p.39, lines } 16 \text { to } 18 \text { ) }\end{array}$ & $\begin{array}{l}\text { Auntie } \\
\text { Toun }\end{array}$ & Kunle \\
\hline
\end{tabular}

Set v

\begin{tabular}{|c|c|c|c|c|}
\hline 12 & & $\begin{array}{l}{ }^{1} \text { Look }(\mathbf{A t}), \underline{\text { Kayode }}(\mathbf{A v}) \text {, you have to }(\mathbf{F m l}) \text { watch what you say } \\
\text { to me! }{ }^{2} \text { Okay (At)? }{ }^{3} \text { Why should }(\mathbf{F m l}) \text { a civil servant talk in this } \\
\text { manner? } \\
\text { (chap. } 8, \text { p.51, lines } 18 \text { to } 20)\end{array}$ & Kunle & Kayode \\
\hline 13 & 13.1 & $\begin{array}{l}{ }^{4} \text { Are you saying that the contractor will (Fms) also tell other } \\
\text { people about what he has just given me? }\end{array}$ & Kunle & kayode \\
\hline & 13.2 & ${ }^{5}$ You mean what he has given us? & Kayode & Kunle \\
\hline & 13.3 & ${ }^{6}$ Well $(\mathbf{A t}), \underline{\text { okay }}(\mathbf{A t})$, if you... & Kunle & Kayode \\
\hline & 13.4 & ${ }^{7}$ Of course $(\mathbf{A m})$, everybody knows $[\ldots]$ & Kayode & Kunle \\
\hline & 13.5 & ${ }^{8}$ Do you tell even messengers? & Kunle & Kayode \\
\hline & 13.6 & $\begin{array}{l}{ }^{9} \text { Are messengers not members of staff? }{ }^{10} \text { Look }(\mathbf{A t}), \underline{\text { Oga }}(\mathbf{A v}) \text {, } \\
\text { there are no secrets anywhere. }[\ldots]{ }^{11} \text { You have to }(\mathbf{F m l}) \text { transact } \\
\text { with people and you must }(\mathbf{F m l}) \text { cooperate. }{ }^{12} \text { Of course }(\mathbf{A m}) \text {, } \\
\text { weall know that }[\ldots] \\
\text { (chap. } 10, \text { p.65, lines } 6 \text { to } 16 \text { and } 19 \text { to } 21)\end{array}$ & Kayode & Kunle \\
\hline 14 & 14.1 & ${ }^{13}$ Which bag? & Kayode & Kunle \\
\hline & 14.2 & ${ }^{14}$ You're asking me? & Kunle & Kayode \\
\hline & 14.3 & $\begin{array}{l}{ }^{15} \text { Shouldn't }(\mathbf{F m l}) \mathrm{I} ? \\
\text { (chap.14, p.84, lines } 5,8 \text { and 10) }\end{array}$ & Kayode & Kunle \\
\hline
\end{tabular}


$15 \quad 15.1 \quad{ }^{16}$ How do we get our share now?

Kayode Kunle

15.2 ${ }^{17}$ Which share? ${ }^{18}$ Don't you understand what I am saying? ${ }^{19}$ Do you want me to bring my salary for sharing?

(chap.14, p.88, lines 12 to 15)

$16 \quad 16.1 \quad{ }^{20}$ Do you think I did not suspect...

$16.2{ }^{21}$ What did you suspect?

16.3 ${ }^{22}$ You thought I didn't know why you waited last night?

Kunle Kayode

$16.4{ }^{23}$ And why did I wait, if I may (Fml) ask? (chap.14, p. 89, lines 4 to 9)

$17 \quad{ }^{24}$ Look (At), Oga(Av), I hold you in high esteem! ${ }^{25}$ That's why! Kunle Kayode Kayode Kunde Kunle Kayode Kayode Kunle ${ }^{26}$ Otherwise, nobody can (Fml) look me in the face and make Kayode Kunle such a grievous allegation. ${ }^{27} \mathrm{But}$ even then, that must (Fml) stop. ${ }^{28}$ After all (Ao), whose money are we talking about? ${ }^{29}$ What did you sell? ${ }^{30}$ What did the ministry sell? [... ${ }^{31}$ Yes (At)? ${ }^{32}$ What did we sell? ${ }^{33}$ Who was the buyer? ${ }^{34}$ What was the rate? ${ }^{35}$ Which receipt did we issue? ${ }^{36}$ And why did we not bank the cash?... ${ }^{37} \mathrm{Look}(\mathbf{A t}) \underline{\mathrm{Oga}}(\mathbf{A v})$, if it is a joke, I don't like it. ${ }^{38}$ I don't like it at all. ${ }^{39} \mathrm{I}$ don't play with matters of this nature.

(chap.14; p.89, lines 15 to 20 and lines 25 to $27,+$ p.90, lines 11 to 14)

\section{Set vi}

18

${ }^{1}$ You did not feel it was important? ${ }^{2}$ Which one was not Governor Kunle important: the resignation or the discussion? ${ }^{3}$ What kind of public servant are you? ${ }^{4}$ Do you know how many citizens from this state applied to be commissioners?

(chap.19, p.122, lines 14 to 18)

${ }^{1}$ Was this young man detailed to get me? ${ }^{2}$ Was the deal

Kunle

(thinking)

Kunle

negotiated? ${ }^{3}$ And was it a trap? ${ }^{4}$ Will (Fms) the intending accuser become the accused? ${ }^{5}$ What embarrassment that would (Fms) be if I got arrested!

(chap.10, p.62, lines 20 to 23)
${ }^{6}$ Wasn't I becoming too reckless? ${ }^{7}$ Why should (Fml) I ask him to do the checking? ${ }^{8}$ Wasn't I exposing myself? ${ }^{9}$ Why was I encouraging my subordinate to intrude into the whole affair to this ridiculous extent? ${ }^{10}$ Wasn't I going to miss a means of getting engineer arrested?

(chap.10, p.63, lines 21 to 26)

${ }^{11}$ For instance, why didn't he want to hear about the bag any longer? ${ }^{12}$ Why did he want to share from the money

$\begin{array}{ll}\text { Kunle } & \text { Kunle(hi } \\ \text { (thinking) } & \text { mself) }\end{array}$

Kunle

Kunle (thinking) (himself) 
and not the loss? ${ }^{13}$ Was he the proverbial man who would (Fms) join you to lick oily hands and desert you as you lick bloody fingers?

(chap.14, p.85, lines 23 to 27)

${ }^{14}$ Why not call a spadea spade? ${ }^{15}$ For instance, why not tell
Kunle
the military intruder that he is a thief? ${ }^{16}$ That he is corrupt
(thinking)
be in the government house to start with? ${ }^{18}$ That he has
(himself)
been paying lip service to the development of the state and
giving effect to self-enrichment? ${ }^{19}$ Why not blow it to his
face that, for the short time he had been around, he was the
chief crook in the state? ${ }^{20}$ Why should (Fml) you lie that
you have enjoyed working with a thief? ${ }^{21}$ Have you really
(Ao)? ${ }^{22}$ When did you start enjoying? ${ }^{23}$ And what, in truth
(Ao), did you enjoy? ${ }^{24}$ How long did the enjoyment last?
${ }^{25}$ Then, what identifiable achievements had the state and
Federal Governments recorded, other than the cowing of
the citizenry and the silencing of journalists? ${ }^{26}$ Yet, you are
talking of achievements. ${ }^{27}$ Which achievements are you
talking about; the steady popularization of corruption?
${ }^{28}$ Besides, what is wrong with your health?
(chap.16; p.107, lines 10 to 24 , + p.108, lines 1to 4).

Taking into account those who respectively play the roles of addresser and addressee in each passage, the twenty-two passages are shared out into seven (7) sets as follows:

Passage $\mathrm{N}^{\circ} \quad$ Interactants

$\begin{array}{lll}\text { Set i } & 1,2 & \text { Kunle and Abeji } \\ \text { Set ii } & 3,4,5 & \text { Kunle and Akwa } \\ \text { Set iii } & 6,7,8 & \text { Kunle and Mother } \\ \text { Set iv } & 9,10,11 & \text { Kunle and Auntie } \\ \text { Set v } & 12,13,14,15,16,17 & \text { Kunle and Kayode } \\ \text { Set vi } & 18 & \text { Kunle and Governor } \\ \text { Set vii } & 19,20,21,22 & \text { Kunle (and his own conscience) }\end{array}$

Thus, we can easily notice that Kunle, the main character of the whole novel, does remain main in these selected corpus-passages; that is important for the full validity of the analyses. In the process of the forthcoming discussion, the sets of passages (i through vii) are considered one after the other.

Any reader of the novel is supposed to know that:

(i) Kunle and Abeji are fiancés; 


\section{Macrothink}

(ii) Kunle and Akwa are friends;

(iii) Kunle and Mother are in adult son / mother relationship;

(iv) Kunle and Auntie are in adult nephew / aunt relationship;

(v) Kunle and Kayode are in boss / assistant relationship;

(vi) Kunle and Governor are in authority / higher authority relationship;

(vii)Kunle is a newly appointed authority.

Then, it is reasonable to assume and expect that:

(i) As fiancés, Kunle and Abeji talk to each other in an informal way showing that there is almost equal power, frequent contact and high affective involvement between them;

(ii) As friends, Kunle and Akwa's talks are informal with indications of equal power, frequent contact and high affective involvement;

(iii) As adult son and mother, Kunle and his mother use a form of language showing almost equal power, frequent contact and high affective involvement;

(iv) As adult nephew and aunt, Kunle and Auntie address each other with a fairly equal power (though the aunt may have more power), with indications of a fairly frequent contact and a fairly high affective involvement;

(v) As a civil service authority or boss and his personal assistant, the interactions between Kunle and Kayode are rather formal with indications of unequal power (the boss obviously having more power than his assistant), despite the frequent contact, hardly showing any signs of affective involvement;

(vi) In their respective positions of authority and higher authority, Kunle's and Governor's talks have the characteristics of formal language showing unequal power, infrequent contact and hardly any affective involvement;

(vii)As a newly appointed authority, Kunle's conscience directly tells him what to do in order to succeed in his mission.

Let all these seven assumptions and expectations rather be considered as hypotheses. To check the (degree of) validity of these hypotheses, we need to tackle the discussion of the Mood patterns in the selected passages.

\subsection{Description and Attempt of Interpretation}

It is worth recalling and keeping in mind Eggins' (2004:187) statement: "The systems of Mood and Modality are the keys to understanding the interpersonal relationships between interactants".

\subsubsection{The Choice of Mood Types}

The different mood types used in the sets of passages are statistically captured in this table. 
Table 3. Mood type distribution in the sets of passages

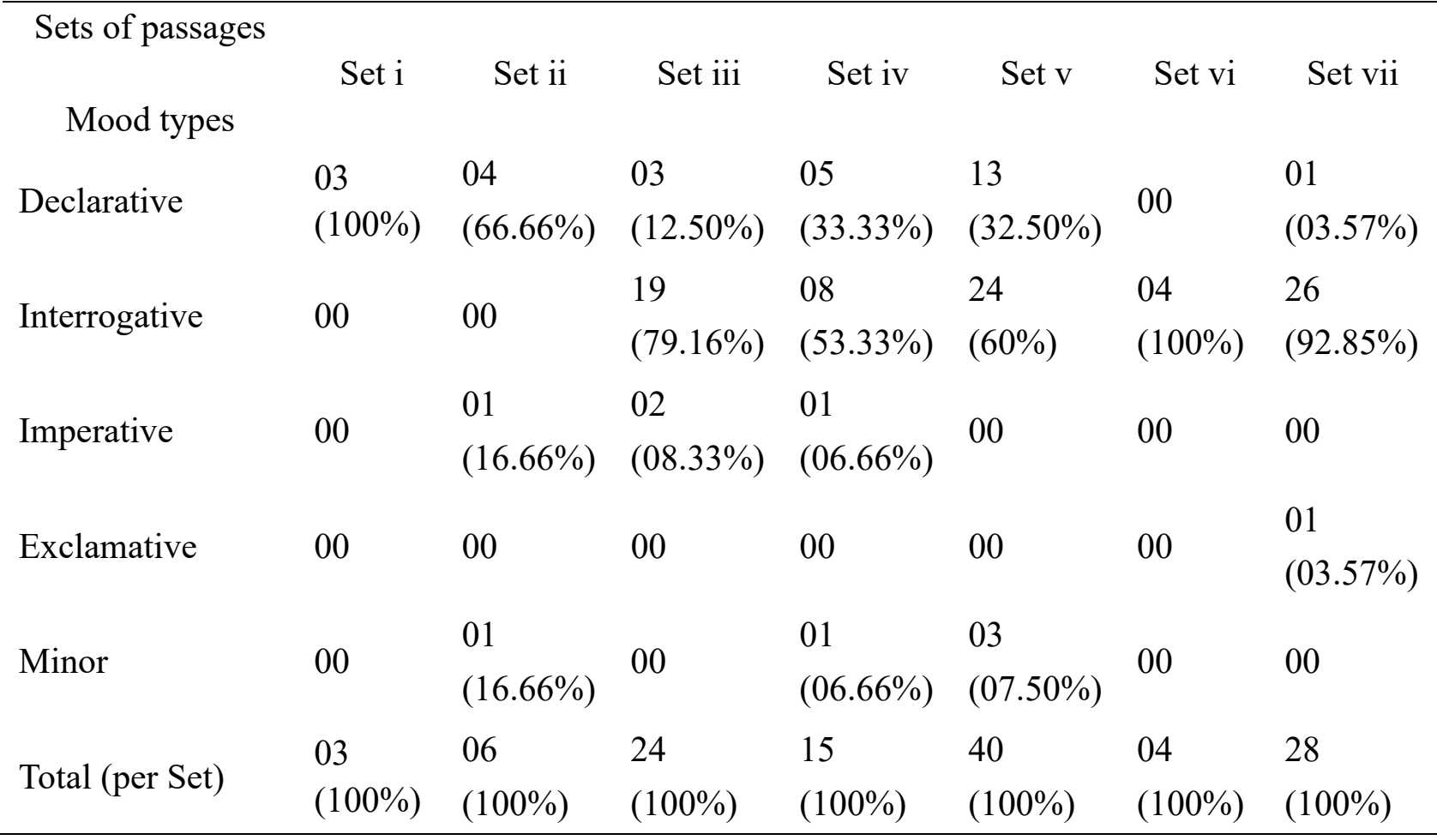

- In Set i (Interactants = Kunle and Abeji)

Set $\mathrm{i}$ consists of the declarative mood only. We have three statements, all made by one interactant: Abeji (addressing Kunle as her fiancé). The fact that the selection does not include Kunle's speech in this set does not necessarily mean that he is silent when Abeji talks, but it may be an indication that the latter dominates the dialogue at the source (in the novel) from which the passages have been selected.

\section{- $\quad$ In set ii (Interactants = Kunle and Akwa)}

The declarative mood occurs four times, making the highest (almost 67\%) mood type choice in the Set. In this lot, one statement is made by Akwa: $\mathrm{S}_{3}$. It is not a piece of information that Kunle needs as such, but it is mainly meant to convince him to do what everybody does: stealing. The other three statements $\left(\mathrm{S}_{4}, \mathrm{~S}_{5}\right.$ and $\left.\mathrm{S}_{6}\right)$, made by Kunle, function as a challenge or a protest to the one made by Akwa. The command made through the imperative mood in $\mathrm{S}_{2}$ functions to contribute to (Akwa's) talking Kunle into doing what everybody does, that is, taking bribes.

\section{- In Set iii (Interactants = Kunle and Mother)}

Here, the predominant mood type is the interrogartive mood: 79\%. This reflects the very large number of questions asked by Mother (to Kunle). In fact, Passage 6 alone consists of no other speech function than questions: from $\mathrm{S}_{1}$ to $\mathrm{S}_{6}$. They are questions asked successively and immediately one after the other in the same speech turn, without any pause to let the interlocutor answer. So there is a phenomenon that can be called interrogative mood accumulation. Mother, who asks those questions, does not necessarily expect the addressee (Kunle) to answer. She is not really asking for information; she rather expresses her feeling of 
indignation by trying to confuse Kunle and convince him to accept bribes (in passages 6 and 7) and not to resign from the post of commissioner (passage 8).

The same goes with passages 7 and 8: interrogative mood accumulated six times in passage 7 and seven times in passage 8 . Kunle is not given time to answer the flows of questions even if he wanted to respond at all. "I couldn't say a word", he admits as a narrator on page 34. All the time mother blows off with series of unanswered questions, very few times does Kunle venture brief statements by way of response. His speech is hardly significant. There is no wonder, therefore, that it is not selected to be part of the Set. Mother clearly dominates the whole speech with her flows of unanswered questions.

\section{- In Set iv (Interactants = Kunle and Auntie Toun)}

As the table shows, the interrogative mood is dominant here: $53 \%$. Its use is striking in two respects. On the one hand, in passage 9, especially from 9.1 to 9.4, we can notice a dialogue that consists of "question-question" rather than "question-answer" sequences. Each interactant proves argumentative by asking questions meant to catch out his/her interlocutor and convince him/her to change their mind. Only questions, no answers. Thus, there is a kind of verbal clinch, but without any indication (yet) of which interactant is the "stronger". On the other hand, in passage 11, there is rather an accumulation of questions. The phenomenon of interrogative mood accumulation occurs (from $S_{11}$ to $S_{14}$ ), and the speaker/user of this accumulation is Auntie Toun; the addressee is Kunle. This suggests that, after the fashion of Mother in the preceding Set, here in Set iv Auntie dominates the speech with flows of unanswered questions - still regarding Kunle.

The declarative mood is used by both interactants (Kunle in passage 9.5 and Auntie in passage 10), suggesting clues of acknowledgements. However, the above-mentioned interrogative mood accumulation occurs subsequently; this suggests a sudden revival of Auntie's viguour as she has set out to convince Kunle. This sudden revival, which turns out to result in the speech domination announced above, is crowned and further given shape with the use of the imperative mood (in $\mathrm{S}_{9}$ ) amidst the declarative mood in the very middle of passage 10. Considering the choice of mood types, all this contributes to showing that Auntie dominates the talks between her and Kunle.

\section{- In Set v (Interactants $=$ Kunle and Kayode)}

In this Set again, the interrogative mood is predominant: $60 \%$. This high percentage results from both "question-question" sequences and the phenomenon of accumulation. "Question-question" sequences occur in passages 13, 14, 15 and 16. In passage 13.2 for instance, Kayode asks "You mean what he has given us?" (in $\mathrm{S}_{5}$ ) to rectify, as he wishes, part of Kunle's question asked in $\mathrm{S}_{4}$. In passage 13.6, what his (Kayode's) question suggests is even more than a rectification to Kunle's question which is in passage 13.5; asking if messengers are not members of staff (in $\mathrm{S}_{5}$ ) implies that Kunle should not ask his question contained in $\mathrm{S}_{8}$ at all. In other words, the question asked in $\mathrm{S}_{8}$ by Kunle is seen by Kayode as a silly question. Were it not for space constraint, if we continued trying to look into and account for the dialogic structure of all the "question-question" sequences in this Set, we would realize that none of these questions is a request of clarification. Instead, they exclusively function to express mutual accusation and a sustained challenge in a highly 
controversial situation between the interactants.

The interrogative mood accumulation, used by Kayode, occurs in passage 17, more specifically from $\mathrm{S}_{28}$ to $\mathrm{S}_{36}:{ }^{28}$ After all, whose money are we talking about? ${ }^{29}$ What did you sell? ${ }^{30}$ What did the ministry sell? ${ }^{31}$ Yes? ${ }^{32}$ What did we sell? ${ }^{33}$ Who was the buyer? ${ }^{34}$ What was the rate? ${ }^{35}$ Which receipt did we issue? ${ }^{36}$ And why did we not bank the cash? Looking closely at these questions, and knowing the story they relate to, we can admit that, obviously, the answers should respectively be: "28 Nobody; ${ }^{29}$ Nothing; ${ }^{30}$ Nothing; ${ }^{31}$ Nothing; ${ }^{32}$ Nothing; ${ }^{33}$ Nobody; ${ }^{34}$ Nothing (No sale, so no rate); ${ }^{35}$ None (No sale, so no receipt); ${ }^{36}$ Because it is illegal money." However, the author of those questions would not be able to respond to them even if he were given time to do so. If he did by giving the just-listed answers, that would rather amount to confessing his guilt in the controversial issue under discussion between them. Thus, there is no wonder that the flow of questions occurs without any response(s) at all; it can rightly be inferred that the questions are meant to show how largely Kayode dominates the dialogue - better called dispute.

Regarding the declarative mood, it is also quite significant in this Set: $32.50 \%$. It mostly occurs in Kayode's speech turns, especially in passage 13.6 (through $\mathrm{S}_{10}, \mathrm{~S}_{11}, \mathrm{~S}_{12}$ ) and in passage 17 (through sentences 24 to 27 and 37 to 39). As from passage 13.6, this declarative mood produced by Kayode starts functioning as statements that express not information as such, but threat or kinds of moral lessons to Kunle. It keeps functioning as a threat by occurring at the beginning of passage 17: "Look, Oga, I hold... that must stop." Then it gives way to the interrogative mood accumulation (explained above), which functions to further and more strongly express the threat. By occurring again at the end of passage 17 ("Look Oga, if it is... of this nature"), and carrying the same function of threat, it eventually contributes to showing that Kayode does indeed dominate the verbal interaction.

\section{- In Set vi (Interactants = Kunle and Governor)}

Set vi consists exclusively of the interrogative mood: four questions addressed successively without any pause, by Governor to Kunle. So, the interrogative mood accumulation occurs here again: ${ }^{1}$ You did not feel it was important? ${ }^{2}$ Which one was not important: the resignation or the discussion? ${ }^{3}$ What kind of public servant are you? ${ }^{4}$ Do you know how many citizens from this state applied to be commissioners?

(This passage occurs when Kunle has come to the Governor to announce his resignation from the post of commissioner. As the latter asked him why he did not discuss his intention with him before writing the resignation letter, he replied that he didn't feel it was important.)

Interestingly, the reader knows or can successfully guess the answers Kunle has in mind for each of the four questions: "1No / of course, I didn't; ${ }^{2}$ the discussion; ${ }^{3} \mathrm{~A}$ good one; ${ }^{4} \mathrm{How}$ can I know? / I don't care."However, the Governor is aware that he (Kunle) would not have the courage to voice those answers, given the hierarchical difference of authority between them. Instead, the flow of questions is meant to show that the Governor dominates the dialogue, and that Kunle is certainly doomed to be reduced to silence or, at best, to apologize.

\section{- In Set vii (Interactants $=$ Kunle and his inner voice)}

The greatest part of the mood type used in this Set is interrogative: almost 93\%. There is interrogative mood accumulation throughout the Set, in all the passages. It consists of 
questions addressed by Kunle to himself as he meditates. In passage 19, the questions relate to Engineer the briber and to Kunle himself, especially what will become of him. In passages 20 and 21, they relate to Kayode and to Kunle himself, especially his own attitude toward higher political authorities. The occurrence of all these flows of questions suggests that Kunle is mentally tortured and almost at his wits' end regarding the relationships between him and his colleagues or political hierarchy.

\subsubsection{Modality Features}

First, the modality items that occur in each of the seven Sets of passages are statistically captured in this table.

Table 4. Modality items distribution in the sets of passages

\begin{tabular}{llllllll}
\hline & Set $\mathrm{i}$ & Set ii & Set iii & Set iv & Set v & Set vi & Set vii \\
\hline modalizers & 01 & 00 & 01 & 01 & 02 & \multirow{2}{*}{00} & 03 \\
& $(25 \%)$ & $(00 \%)$ & $(20 \%)$ & $(16.66 \%)$ & $(22.22 \%)$ & & $(50 \%)$ \\
modulators & 03 & 02 & 04 & 05 & 07 & \multirow{2}{*}{00} & 03 \\
& $(75 \%)$ & $(100 \%)$ & $(80 \%)$ & $(83.33 \%)$ & $(77.78 \%)$ & & $(50 \%)$ \\
Total of modality & 04 & 02 & 05 & 06 & 09 & \multirow{2}{*}{00} & 06 \\
items (per Set) & $(100 \%)$ & $(100 \%)$ & $(100 \%)$ & $(100 \%)$ & $(100 \%)$ & & $(100 \%)$ \\
\hline
\end{tabular}

\section{- In Set i (Interactants = Kunle and Abeji)}

There are three modulators and one modalizer in the Set. All of them are used by Abeji addressing Kunle. The high modulators "have to" (in $\mathrm{S}_{1}$ ) and "must" (in $\mathrm{S}_{3}$ ) bluntly express obligation. Their use suggests that the addresser exercises some authority over the addressee. They constitute an expression of pressure. The use of the high modalizer "I know" (in $\mathrm{S}_{2}$ ), a grammatical metaphor which is even more assertive than "I am sure", coupled with "cannot" regarding the addressee, is an expression of judgement that further suggests Abeji's authority in exercising pressure on Kunle.

\section{- In Set ii (Interactants = Kunle and Akwa)}

There are two modulators but no modalizer. The first modulator is "will" (in $\mathrm{S}_{5}$ ); beyond the role of future tense modal, it serves to express an attitude: Kunle's determination not to take bribes. The second one, "must" (in $\mathrm{S}_{6}$ ), is a case of modulation that serves to express an opinion: Kunle's judgement of the way things happen in the country. So, Kunle expresses his attitude and opinion freely, directly and strongly. Thus, modulation serves Kunle to express his firm position against the practice of bribery which his friend urges him to adopt.

\section{- In Set iii (Interactants = Kunle and Mother)}

Here, there is one modulator ("can't") which occurs four times, and one modalizer ("will") which occurs once. The modulator "can't" (in $\mathrm{S}_{9}, \mathrm{~S}_{10}$ and $\mathrm{S}_{11}$ ) occurs repeatedly and rhetorically to play the role of " mustn't / shouldn't / oughtn't". In fact, structurally, the clauses in $\mathrm{S}_{9}, \mathrm{~S}_{10}$ and $\mathrm{S}_{11}$ are polar interrogatives, but they are actually equivalent, respectively, to "You should reason", "You should learn something from your father's woes"; "You should talk to your head". So, besides being part of the interrogative mood 
accumulation discussed above, they constitute a repeated expression of high modulation as well. Thus, they contribute to further showing the high degree of authority, pressure and power in Mother's speech addressed to Kunle.

Beyond its role of future tense indicator, the modal operator "will" in $\mathrm{S}_{17}$ functions as a modalizer expressing a risk, a very high probability, a high degree of certainty. It suggests the speaker's absolute certitude, her assertiveness and, in some respects, a high extent of authority wherein there is no room for doubt. The imperative "don't go astray" (in $\mathrm{S}_{12}$ ), occurring in the midst of accumulated interrogative mood, reinforces the feeling that Mother's speech denotes absolute certitude, assertiveness and authority.

\section{- In Set iv (Interactants = Kunle and Auntie Toun)}

As the table shows, this Set contains five modulators and one modalizer. Two modulators are used by Kunle: "have to" (in $\mathrm{S}_{6}$ ) and "must" (in $\mathrm{S}_{7}$ ). These two modulators express obligation for the sake of self-discipline. So their use suggests that Kunle puts pressure on himself to be upright. As for the three modulators used by Auntie Toun, it is the repetition of "must" (in $\mathrm{S}_{8}$, $\mathrm{S}_{9}, \mathrm{~S}_{10}$ ). She uses this modulator to dictate some attitudes, especially obligations to Kunle. Hence, one can infer that she uses modulation to show authority, put pressure and exercise power over her interlocutor, namely Kunle.

The modalizer "ever", which expresses a high degree of usuality - though negative, is used (by Auntie Toun) within an imperative. The simultaneous use of the high modalizer and the imperative mood makes this command extremely strong. This contributes to revealing the high degree of authority and power in Auntie Toun's speech addressed to Kunle.

\section{- In Set $v$ (Interactants $=$ Kunle and Kayode)}

There are two modalizers in this Set, but as many as seven modulators. The first modaliser "will" (in $\mathrm{S}_{4}$ ) has been used by Kunle, serving mainly as a future tense operator. The second one, "may" in $\mathrm{S}_{23}$, has been used by Kayode. It denotes false, ironic deference in that it serves to express request of permission after - rather than before - an act. As for the modulators, Kunle has used two of them while warning Kayode to mind his Ps and Qs: "have to" (in $\mathrm{S}_{1}$ ) and "should" (in $\mathrm{S}_{3}$ ). Their use reflects his feeling of indignation regarding his assistant's language and attitude.

Five modulators have been used by Kayode: "have to" and "must" in $\mathrm{S}_{11}$, "shouldn't" in $\mathrm{S}_{15}$, "cannot" in $\mathrm{S}_{26}$ and "must" in $\mathrm{S}_{27}$. The first two - "have to transact" and "must cooperate" (in $\mathrm{S}_{11}$ ) - particularly function to help give instructions in the form of moral lessons. That is almost true of the last modulator, that is, "must" in "that must stop" (in $\mathrm{S}_{27}$ ), since $\mathrm{S}_{27}$ is actually equivalent to "you must stop [doing] that". Such use of modulators contributes to suggesting some degree of authority and power in the speaker.

\section{- In Set vi (Interactants = Kunle and Governor)}

There are no modulators and no modalizers here. So, without necessarily seeking (yet) to account for that, let us go over to the next Set.

\section{- In Set vii (Interactants = Kunle and his inner voice)}

Three modalizers and three modulators come from Kunle's inner voice as he talks with his own conscience, that is, when he asks himself questions. The three modalizers, which are "will" in $\mathrm{S}_{4}$, "would" in $\mathrm{S}_{5}$ and "would" in $\mathrm{S}_{13}$, relate to some of the risks he runs in his office 
by adopting his firm position regarding bribery. The three modulators are "should" in $\mathrm{S}_{7}$, "ought not" in $\mathrm{S}_{17}$, "should" again in $\mathrm{S}_{20}$; the one in $\mathrm{S}_{7}$ and in $\mathrm{S}_{20}$ being directly related to the appropriateness of his own attitude. This occurrence of both modalizers and modulators in the course of Kunle's meditation suggests the seriousness of the interpersonal relationship problems that he faces.

Given the description and attempt of interpretation done so far, what tenor dimensions do the data imply?

\subsubsection{Tenor Dimensions Inference}

\section{- In Set i (Interactants = Kunle and Abeji)}

Remember, from the examination of the choice of mood types, it appears that Abeji presumably dominates the dialogues between her and Kunle. On the other hand, the exploration of modality features has shown her use of high modulators and modalizers, suggesting pressure, assertiveness, authority over Kunle. So, the power is unequal; Abeji has the higher power. Regarding the affective involvement, it is hardly shown; there is hardly any indication of high affective involvement, nor any of low affective involvement as such. As for the frequency of contact between the two interactants, one might believe that Abeji's use of high modulators and modalizers results from frequent contact. However, there is no reciprocity of such language use. So we can just maintain and stick to what has been already inferred from the use of modulators and modalizers. In fact, basing on the analyses done so far of Set i, one cannot convincingly state that there is almost equal power, frequent contact and high affective involvement between Kunle and Abeji, two fiancé(e)s. Thus Hypothesis (i) is invalidated.

\section{- In Set ii (Interactants = Kunle and Akwa)}

We can remember, from the above examination of the choice of mood types and modality features, that Akwa has set out to convince Kunle to take bribes. But the latter's responses are rather confronting, with modulation that strongly expresses his opinion and opposition (to the practice of bribery). The polarity adjunct "no" in $\mathrm{S}_{4}$ contributes to expressing Kunle's categorical position. Thus the choice of mood types and modality items by both interactants suggests some power balance. The power balance can also be noticed through their reciprocal use of first names ("Kunle" in $\mathrm{S}_{1}$ and "Akwa" in $\mathrm{S}_{4}$ ), let alone the teasing relationship that is shown through the use of the informal vocative "old boy" (in $\mathrm{S}_{3}$ ) by Akwa. From all these language features, it can be inferred that these two interactants have almost equal power, are in frequent contact and show some high affective involvement. Thus Hypothesis (ii) is validated: as friends, Kunle and Akwa's talks are informal with indications of equal power, frequent contact and high affective involvement. Of course, there seems to be a bit more power bestowed upon Akwa who manifests his constant effort to convince Kunle through many a device: among others, the just-mentioned teasing vocative "old boy" (though it occurs only once), and the use of the common continuity adjunct "Look" - not to be mistaken for the imperative proper (in $\mathrm{S}_{1}$ and $\mathrm{S}_{3}$ ).

\section{- In Set iii (Interactants =Kunle and Mother)}

It has been noted from the above subsections, that Mother's speech is characterized by frequent accumulation of interrogative mood which is meant to express her indignation, to 
choke Kunle into silence, to talk him into accepting bribes and never resigning from his post of commissioner. It is also characterized by high modulation and high degree of modalization, suggesting absolute certitude and assertiveness. Of course, the reader might rightly have the impression that the occasional co-occurrence of the comment and vocative adjuncts "Please son" (in $\mathrm{S}_{12}$ ) tempers Mother's speech some time. However, judging from the course of the interaction, it may be a misnomer to definitely take these two adjuncts as expressions of politeness and heartfelt affection. In fact, most of the mood and modality features in Mother's speech rather imply that there is unequal power (with Mother in higher power), and low affective involvement. The contact is rather questionable though it can be rated as frequent; we shall briefly revert to this dimension in the final interpretation below. By way of recapitulation, we can say that there is completely unequal power, rather low affective involvement, and 'problematic' frequency of contact. Thus Hypothesis (iii) is not validated: contrary to what we expected, adult son and Mother are not in almost equal power, nor are they in clearly frequent contact and high affective involvement.

\section{- In Set iv (Interactants = Kunle and Auntie Toun)}

Condensed, the description of Auntie Toun's language - made previously - goes as follows: heavily punctuated with what we have agreed to call interrogative mood accumulation, confronting questions to answer back Kunle's, frequent modulation and high degree of modalization. Thus, even though there is a series of question-question sequences suggesting a serious argument between her and Kunle, it can eventually be admitted that the power is unequal, that Kunle is just defending himself, that Auntie Toun does hold the higher position of power. Auntie's language (use) does not include any features of high affection, nor does Kunle's. Of course, one might be tempted to think of the vocative adjunct "Auntie", preceded by the continuity adjunct "okay" (in Prop 39), as an affective involvement and frequent contact indicator. Even if it were such an indicator, 'one swallow doesn't make a summer", as the saying goes. It is not a regular pattern, but an occasional or even accidental one, rather functioning as a device for Kunle to stop the argument and get rid of Auntie. We can ultimately retain that there is unequal power, rather low affective involvement, and 'problematic' frequency of contact between these two interactants: adult nephew and aunt are not in slightly unequal power, high affective involvement and frequent contact as we could expect.

\section{- In Set v (Interactants $=$ Kunle and Kayode)}

To recall the account of mood type choice and modality features in Set $v$, it is worth rementioning, on the one hand, that there is a series of question-question sequences indicating a serious argument, and that there is also some frequent use of modulation by both interactants. This double fact suggests equal power. Nevertheless, the recurrence of interrogative mood accumulation and some significant rate of threat-expressing declarative mood in Kayode's speech, is not to be forgotten too soon. This recurrence suggests Kayode's domination of the interaction as notified earlier.

Besides, this set of passages contains other Mood items or features having something to do with Kayode's domination of the interaction and, accordingly, some tenor dimension(s). For instance, out of anger, he dares to interrupt Kunle (in $\mathrm{S}_{6}$ and $\mathrm{S}_{20}$ ) and take the floor; it takes audacity, arrogance or excessive self-empowerment, as it were, to do so to one's boss. The 
comment adjunct "After all" (in $\mathrm{S}_{28}$ ) serves him to make his opinion peremptory; it conveys an unusual, insolent attitude towards one's boss. He dares to say "yes?" (in $\mathrm{S}_{31}$ ) to Kunle, a "yes" of rising tone if considered orally, meaning "Come on! Answer my questions"; this too suggests audacity and arrogance towards the boss. Even more striking is his use of the pseudo imperative "Look" (labelled continuity adjunct) and the vocative adjunct "Oga" (in $\mathrm{S}_{10}, \mathrm{~S}_{24}$ and $\mathrm{S}_{37}$ ) which do not only denote informal face-to-face interaction but also function as what we can call 'threat starters'. Kunle, who is the boss, has used a 'threat starter' only once (in $\mathrm{S}_{1}$ ) while, paradoxically, Kayode, the assistant, has made use of that several times. All those Mood features contribute to showing that Kayode is bestowed with more power than Kunle and that there is very low affective involvement in their interaction. Thus Hypothesis (v) is not validated: here is a civil service authority or boss in lower power than his personal assistant, with very low affective involvement between the two interactants.

\section{- In Set vi (Interactants = Kunle and Governor)}

As partially concluded when dealing with this Set in subsection 4.2.1, there is prevailing use of the interrogative mood accumulation by Governor to show his domination of speech over Kunle. Without any modality features, this domination can be translated into power and low affective involvement. Thus Hypothesis (vi) is validated: between the Commissioner (who is an authority) and the Governor (who is a higher authority), there is unequal power with more power ascribed to the Governor, no affective involvement. There is no indication of frequent contact; so it can be maintained that the contact is rather occasional.

\section{- In Set vii (Interactants $=$ Kunle and his inner voice)}

By way of reminder, this Set essentially consists of the interrogative mood accumulation. There are flows of questions that Kunle asks himself regarding the relationship between him and the other interactants. This, as we remarked, suggests a serious argument between him and his own conscience. We have also noticed the occurrence of both modalizers and modulators suggesting the seriousness of the interpersonal relationship problems that he faces. The comment adjuncts "really" (in $\mathrm{S}_{21}$ ) and "in truth" (in $\mathrm{S}_{23}$ ) contribute to confirming or reinforcing this idea. Thus, although it seems awkward to talk of some tenor relationship as such between a person and their own conscience, we can reasonably infer that there is a kind of unequal power and low affective involvement between him and his conscience. Therefore, Hypothesis (Vii) is not validated: rather than dictating him how to act, his conscience asks him questions that plunge him in serious meditation.

Now let us go for the general interpretation.

\subsection{Recapitulation and Further Interpretation}

Almost all the hypotheses set for the outcome of the analyses in this paper have failed (to be validated). Why?

Take the first hypothesis, which relates to the relationship between a young woman and her fiancé, i.e. a man and his fiancée. In our (universal) culture, and more specifically in a West African - though 'modern' - culture, the woman is not expected to dominate the speech, be in higher power, exercise pressure and hardly show any affective involvement in talks; at least, not the way and under the circumstances in which it happens here. The rather paradoxical tenor manifestation revealed here suggests that the two fiancé interactants embody something 
else than ordinary fiancé(e)s in the romantic sense. The woman embodies love heavily conditioned by material, and here, it is material that would be easily gained from bribery. The man embodies firm opposition to bribery at the risk of losing his fiancée or lover.

Consider the second hypothesis, which concerns the friend/friend tenor relationship in the interaction. True, it has been validated, for the two friends have almost equal power, are in frequent contact and reciprocally show some high affective involvement. However, as shown earlier, there seems to be a bit more power bestowed upon Akwa. Why? Why are both friends not assigned the same degree of power? To answer this question, it is worthy of note that the significance of this friendship between Kunle and Akwa is to be judged in relation to the crucial issue of bribery. The motivational relevance of the slight power difference, as it appears, lies in the intention of showing Kunle as an interactant undergoing pressure (from his friend) to accept bribes. Besides, the extra power assigned to Akwa serves him not just as a friend, but also as a friend adviser and, above all, a conformist exhorting his friend to do what everyone does. Kunle, by contrast, whose speech essentially functions as refusal to the last, rather embodies nonconformism.

Even the hypothesis related to the tenor dimensions between adult son and mother (that is, Hypothesis iii) has been invalidated. There is sharply unequal power, low affective involvement and lack of language-feature evidence for frequent contact. That is a most curious case. Admittedly, a mother is absolutely supposed to have more power than her son. All the same, it is also a matter of fact that an adult son ought to be addressed with no or very little authority from his mother. (Let us consider that as 'Principle 1', noting that it has been violated in the text under analysis.) We know too, on principle, that mothers and sons usually show affection in addressing each other. (Let us consider that as 'Principle 2', noting that it has also been violated as regards the relationship between Kunle and his mother.) Third, it is a matter of course that mothers and their offspring always seeing each other and talking to each other, use language with features denoting frequent contact. (Considering that as 'Principle 3', we can say that it has hardly been abided by in the text under consideration.)

So, language, as used by Kunle and his mother - mostly by the latter, functions to violate our three so-called principles. Ultimately, that may not be surprising if we regard Mother not just as mother, but as the most influential person (parent) in charge of exercising the maximum of pressure to break Kunle's reluctance about bribery. These two interactants are to be thought of beyond the respective roles of mother and son as one can fancy in daily expected circumstances. In most of their interaction, they can rightly be thought of as 'blind-attachment-to-material-interest' (for mother) and 'firm-attachment-to-dignity' (for son) talking to each other in the context of saying yes or no to bribery.

The case of Hypothesis (iv), which concerns the relationship between adult nephew and aunt, is quite similar to the one we have just closed. It has been invalidated, as a result of the above three language-use social principles being violated. Of course, if you believe that mother/son and aunt/nephew relationships do not imply exactly the same affective involvement and the same contact frequencies, you might be right. Leaving these two dimensions aside and focussing on power dimension, we can still admit that an aunt has power over a nephew. Now, here in the text under analysis, the aunt (Auntie Toun) is ascribed much more power than the adult nephew (Kunle). It seems it can't be any other way for an aunt who is meant to embody 
'blind-attachment-to-material-interest' (just as Mother and even the fiancée considered above) facing a nephew who rather embodies 'firm-attachment-to-dignity' in the context of accepting or rejecting bribery.

Let us go back to Hypothesis (v) now, regarding the boss/assistant tenor relationship in the text. It is quite normal that the power should be unequal, the affective involvement rather low and the contact not too frequent between a boss and his assistant. But according to our (universal) culture, who of the boss or the assistant ought to be assigned the higher power? How low should the affective involvement be? And how frequent should the contact be? Obviously, the boss ought to have the higher power. Paradoxically, we witness just the contrary here, for Kayode the assistant is assigned much more power allowing him to dominate the interaction in many respects, while Kunle the boss is reduced to just defending himself, as shown earlier. More often than not, however frequent the contact is, the affective involvement between a boss and his assistant is virtually neutral. Surprisingly enough, here between Kunle and Kayode it is overtly low, indicating a conflict between a boss who keeps resisting bribery, and an assistant who rather sticks to material interest.

You can notice that the phrase 'blind attachment to material interest' has been used several times in this subsection to definitely depict Mother's, Aunt's, Abeji's and Kayode's personalities. So has the phrase 'firm attachment to dignity', to depict Kunle's personality. These seem to be the two extreme personality stereotypes encoded in the corpus. Going back to Hypothesis (vi), which has been validated, we can remember that Governor is assigned more power than Kunle the Commissioner. The fact that there is unequal power between Governor and a commissioner and that the former has the higher power, is only a matter of course; this is an expected tenor dimension. However, looking more deeply into how high Governor's power is - which space constraint prevents from further doing here, we will realize that he (Governor) is actually ascribed too much power. He is worth adding to the list of those embodying 'blind attachment to material interest'. At last, regarding Hypothesis (vii), we can remember that it has not been validated. There is a kind of unequal power and low affective involvement between Kunle and his own conscience, with his own conscience in higher power exercising pressure on him through flows of questions that plunge him in serious meditalion. Considering even the whole lot of interactions analysed thus far, there is no wonder that Kunle, the main interactant, is lost in deep thoughtfulness. In fact, so unusual are the tenor dimensions in these interactions that they can make you feel in a world that has gone crazy. This is a world dominated by bribery adepts who dictate the law, making it a hell for any non-adept who considers changing the order.

Some remarks made above certainly look like a conclusion and they can indeed be rated as a conclusion to the section of practical analysis. Let us go now for a broader conclusion regarding the whole paper.

\section{Conclusion}

We can remember that after the general introduction (Section1), this paper has synoptically reviewed the theory of Mood (Section 2) and some literature related to the application of that theory by a number of researchers (Section 3), before working out the corpus (Section 4). The exploration of the selected passages has revealed several unusual tenor dimensions among the interactants: (i) fiancés whose relationship is characterized by the woman's high pressure 
over the man, showing hardly any affective involvement; (ii) friends of the same age group but unequal power; (iii) a mother who has excessive power over her adult son, showing little affective involvement; (iv) an adult nephew under very high pressure from his aunt, with rather low affective involvement; (v) a civil service assistant exercising pressure on his boss, with remarkably low affective involvement.

There are essentially two types of interactants in the texts under analysis: those who are blindly attached to material interest, and one who is rather firmly attached to his dignity. In fact, the novel raises the eternal issue of the delicate coexistence between a great majority of corruptionists and a very small minority of anti-corruptionists. Sure enough, A silly season is a novel about bribery. Still, basing on the analyses done so far, it seems more informative to state that the novel relates some social malaise and threat of disruption resulting from a single-minded but ultimately vain attempt to sow or restore the sense of rectitude within a corrupt, rotten society

\section{References}

Amoussou, C. Y. (2015). Mood, interpersonal and ideological meaning patterns in the Abiku poems (J. P. Clark, W. Soyinka). International Journal of Language and Linguistics, 2(3), 129-138.

Ayoola, M. (2013). Interpersonal and ideational metafunctions of some selected political advertisements in some Nigerian newspapers. International Journal of Humanities and Social Science, 3(8), 165-178.

Boukari, N. (2015). An inquiry into the impact of contextual features on ideational and interpersonal meanings in Flora Nwapa's selected novels. Unpublished Phd Thesis. UAC.

Djimet, I., \& Alladoum, R. (2019). A mood analysis of the English version of Nicola Sarkosy's Dakar speech. Revue internationale de Linguistique Appliquée, de Littérature et d'Education (RILALE), 2(3), 80-101.

Eggins, S. (2004). An introduction to systemic functional linguistics (2nd Ed.). New York and London: Continuum.

Gbaguidi, C. (2018). Revisiting the issue of resistance to bribery in A S Ogundimu's A silly season. International Journal of Current Innovations in Advanced Research, 1(5), 73-82. https://doi.org/10.31426/ijamsr.2018.1.10.1019

Halliday, M. A. K., \& Matthiessen, C. (2004). An introduction to functional grammar (3rd Ed.). London: Edward Arnold.

Koussouhon, A. L., \&Boukari, N. (2017). An inquiry into the use of vocative adjuncts in Efuru and The concubine: A systemic functional linguistics-oriented contribution. Revue du CAMES / Littérature, Langues et Linguistique; ํ5 du 1er Semestre, 100-121.

Koussouhon, A. L., \& Dossoumou, A. (2015). Analyzing interpersonal metafunction through mood and from critical discourse and womanist perspective. International Journal of English Linguistics, 5(6), 20-33. https://doi.org/10.5539/ijel.v5n6p20

Koutchadé, S. I. (2016). The grammar of interpersonal meaning in Wole Soyinka's A play of giants. Mediterranean Journal of Social Sciences, 7(5), 299-309. https://doi.org/10.5901/mjss.2016.v7n5p299 


\section{Macrothink}

Education and Linguistics Research

ISSN 2377-1356 2020, Vol. 6, No. 2

Koutchadé, S. I. (2015a). Discourse analysis of General Muhammadu Buhari's official acceptance speech: A systemic functional perspective. International Journal of English Linguistics, 5(5), 24-36. https://doi.org/10.5539/ijel.v5n5p24

Koutchadé, S. I. (2015b). Thematic structure and foregrounding in selected extracts from Adetunji Ogundimu's A silly season. International Journal of English and Literature, 5(4), 43-54.

Martin, J. R., Matthiessen, C. M., \& Painter, C. (1997). Working with functional grammar. London: Edward Arnold.

Nur, S. (2015). Analysis of interpersonal metafunction in public speeches: A case study of Nelson Mandela's presidential inauguration speech. The International Journal of Social Sciences, 30(1), 52-63.

Ogundimu, A. S. (2008). A silly season. Lagos: Campus Publications.

Olaniyan, K. K. (2012). Tenor of discourse in General Ibrahim Babangida's independence day broadcasts. Papers in English and Linguistics (PEL), 13, 142-169.

Taiwo, O. (2014). A critical discourse analysis of modals in Nigerian political manifestos. International Journal of Linguistics, 6(3), 109-117. https://doi.org/10.5296/ijl.v6i3.5589

Ye, R. (2010). The interpersonal metafunction analysis of Barack Obama's victory speech. English Language Teaching, 3(2), 146-151. https://doi.org/10.5539/elt.v3n2p146

\section{Copyright Disclaimer}

Copyright reserved by the author(s).

This article is an open-access article distributed under the terms and conditions of the Creative Commons Attribution license (http://creativecommons.org/licenses/by/4.0/). 